\title{
ORIGINAL ARTICLE \\ Contemporary pollen-mediated gene immigration reflects the historical isolation of a rare, animal-pollinated shrub in a fragmented landscape
}

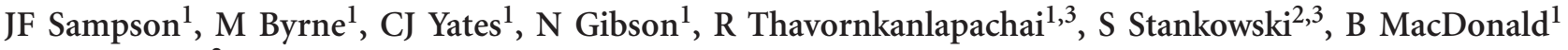 \\ and I Bennett ${ }^{2}$
}

Fragmentation is generally considered to have negative impacts on widespread outbreeders but impacts on gene flow and diversity in patchy, naturally rare, self-compatible plant species remain unclear. We investigated diversity, gene flow and contemporary pollen-mediated gene immigration in the rare, narrowly distributed endemic shrub Calothamnus quadrifidus ssp. teretifolius. This taxon occurs in an internationally recognized biodiversity hotspot subjected to recent human-induced fragmentation and the condition of the remnants ranges from intact to highly degraded. Using microsatellites, we found that inbreeding, historically low gene flow and significant population differentiation have characterized the genetic system of C. quadrifidus ssp. teretifolius. Inbreeding arises from self-pollination, a small amount of biparental inbreeding and significant correlation of outcross paternity but fecundity was high suggesting populations might have purged their lethals. Paternity analyses show that pollinators can move pollen over degraded and intact habitat but populations in both intact and degraded remnants had few pollen parents per seed parent and low pollen immigration. Genetic diversity did not differ significantly between intact and degraded remnants but there were signs of genetic bottlenecks and reduced diversity in some degraded remnants. Overall, our study suggests human-induced fragmentation has not significantly changed the mating system, or pollen immigration to, remnant populations and therefore genetic connectivity need not be the highest conservation priority. Rather, for rare species adapted to higher levels of inbreeding, conservation efforts may be best directed to managing intact habitats and ecosystem processes.

Heredity (2014) 112, 172-181; doi:10.1038/hdy.2013.89; published online 25 September 2013

Keywords: fragmentation; gene flow; diversity; pollen immigration; ironstones; conservation

\section{INTRODUCTION}

Evolutionary processes together with the geological and climatic history of a landscape shape the current genetic structure of plant populations. The mating system, through its impact on gene flow and genetic drift, was found by Duminil et al. (2009) in a recent meta-analysis to be the key factor influencing genetic differentiation among populations. The study of mating systems and gene flow is therefore vital to our understanding of the evolutionary dynamics of populations. Mating systems are widely studied using progeny arrays and molecular markers (Eckert et al., 2010), and historical levels of gene flow among populations have been estimated from measures of genetic differentiation of populations (for example, $F_{\mathrm{ST}}$, Wright, 1951). More recently, long-term equilibrium gene flow has been inferred from migration rates and population sizes using an explicit probabilistic model based on the $n$-coalescent (Kingman, 1982; Beerli, 2006). Estimates of contemporary gene migration and recent gene flow (within the last few generations) can be made using molecular markers and a variety of analytic procedures based on Bayesian methods, parentage analyses or genetic assignment.
Comparing patterns of diversity and gene flow in taxa with divergent mating systems is of interest in the context of fundamental plant evolutionary genetics. Comparisons are also useful for understanding the responses of plant populations to landscape changes and for predicting prospects for persistence. The need for such predictions is increasing because widespread land-clearing for urbanization or agriculture has resulted in many terrestrial ecosystems occurring as mosaics of patches of remnant native vegetation surrounded by a highly altered landscape 'matrix' (fragmentation). For native plant species in these remnants, populations are typically smaller, and more isolated and disturbed, than they were historically and the composition of their pollinator communities may have changed. Smaller, more fragmented populations are predicted by population genetic theory to be prone to reduced gene flow and increased genetic drift and inbreeding (Young et al., 1996). Theoretically, this can result in the depletion of genetic diversity within populations, divergence among populations and inbreeding depression, but predictions are not always realized.

Indeed, several reviews of empirical studies have attempted to identify patterns in the genetic responses of plant species to habitat

${ }^{1}$ Science Division, Department of Parks and Wildlife, Bentley Delivery Centre, Bentley, Western Australia, Australia and ${ }^{2}$ Centre for Ecosystem Management, Edith Cowan University, Joondalup Western Australia, Australia

3Present address: Department of Animal Biology, The University of Western Australia, Nedlands, Western Australia 6009, Australia.

Correspondence: Dr JF Sampson, Science Division, Department of Parks and Wildlife, Locked Bag 104, Bentley Delivery Centre, Bentley, Western Australia 6983, Australia. E-mail: jane.sampson@dec.wa.gov.au

Received 17 December 2012; revised 2 July 2013; accepted 29 July 2013; published online 25 September 2013 
fragmentation (Hobbs and Yates, 2003; Coates et al., 2007; Honnay and Jacquemyn, 2007; Aguilar et al., 2008; Angeloni et al., 2011). These reviews have found that responses cannot be generalized across species but are influenced by factors such as abundance, longevity and particularly the mating system and gene dispersal. For example, Angeloni et al. (2011) found that the effects of inbreeding depression decrease with decreasing natural population size. They attributed this finding to there being either an existing higher level of inbreeding depression in small populations and/or increased impact of purging of deleterious genes in small populations. Hopper (2009) suggested that naturally patchy, localized endemics with strongly differentiated population structure may have features of their genetics and ecology that counter the effects of inbreeding. Interestingly, Aguilar et al. (2008) suggested that, because they have lower genetic diversity with a greater proportion between populations, naturally rare (defined by their narrow geographical range, restricted habitat specificity or small local population sizes), long-lived, selfing or non-outcrossing selfcompatible species may be less susceptible to the reduced gene flow, increased inbreeding and reduced gene diversity associated with fragmentation. However, empirical evidence of the impact of genetic isolation resulting from fragmentation is equivocal (Aguilar et al., 2008; Lander et al., 2010) and there are few studies on contemporary gene migration in rare, self-compatible, mixed-mating species.

Calothamnus quadrifidus ssp. teretifolius A.S. George \& N. Gibson is a species that provides an excellent opportunity to investigate diversity, gene flow and responses to fragmentation in a rare, selfcompatible shrub as it has a small $\left(290 \mathrm{~km}^{2}\right)$, naturally patchy distribution that has been subject to more recent human-induced fragmentation. It is a rare member of a species complex found in the species-rich shrublands of the globally significant southwest Australian Biodiversity Hotspot (Gibson et al., 2012). The genetic structure and effects of fragmentation on this rare taxon can be compared with that of its common and widespread sister subspecies, Calothamnus quadrifidus ssp. quadrifidus R.Br., where investigations have shown high pollen-mediated gene immigration and low differentiation of populations but increased inbreeding and reduced seed production in small populations (Byrne et al., 2007; Yates et al., 2007). The rare C. quadrifidus ssp. teretifolius is largely restricted to shallow soils that have formed over the last two million years on massive ironstone deposits that have a patchy distribution in southern Western Australia. These soils and their associated vegetation communities are like uncommon 'islands' in the landscape. Prior to fragmentation, these shrublands would have intergraded with woodlands occurring over deeper soils but extensive clearing in the early 20th century (mainly between 1901 and 1930) has removed much of the woodlands along with the majority (>95\%) of the shrublands (Gibson et al., 2012). Extant populations of ssp. teretifolius vary in size and occur in local landscapes ranging from isolated, degraded linear strips of vegetation on road verges where the native species have been replaced by weedy grasses, to relatively intact remnants of varying size that still contain a diverse array of native species. Natural patches that are connected to other populations through uncleared vegetation were considered to be representative of the pre-fragmentation landscape. Therefore, estimates of contemporary pollen-mediated gene immigration (pollen immigration) into such populations could be used as an indicator of pollen immigration into populations prior to fragmentation.

In order to study the genetic structure and impact of fragmentation on a rare, self-compatible plant, we investigated the mating system, genetic diversity and migration patterns of degraded and relatively intact remnant populations of C. quadrifidus ssp. teretifolius. We aimed to test the null hypothesis of no reduction in gene flow as a result of recent fragmentation by comparing historical levels of gene flow with estimates of contemporary pollen-mediated gene immigration. A broad aim of the study was to address the general question of whether rare, self-compatible species are less prone to the impacts of fragmentation.

\section{MATERIALS AND METHODS}

\section{Study species}

Calothamnus quadrifidus ssp. teretifolius is a woody shrub that grows to a height of $2-4 \mathrm{~m}$ and flowers profusely during winter and spring. The protandrous, hermaphroditic flowers are borne in dense spikes so that geitenogamous pollination is likely to occur (Gibson et al., 2012). Honeyeater birds (Megaliphidae) and European honey bees (Apis mellifera L. 1758) have been observed visiting the flowers and the species is typically regarded as birdpollinated. Seeds are enclosed in dehiscent woody capsules that persist for many years after flowering. The seed itself is minute, non-endospermous, not dispersed by birds and has no morphological characteristics that would aid dispersal by wind or water (Yates et al., 2007); hence, gene flow through seeds is unlikely to be significant. The species resprouts following wildfires, and by mass recruitment from seeds given favorable seasonal conditions in the year following the fire. Less disturbed populations of ssp. teretifolius with an intact understorey are composed mostly of reproductive adults with low numbers in juvenile and seedling stages. In contrast, in highly disturbed populations with a degraded understorey, seedlings and juveniles are almost entirely absent (Gibson et al., 2012), suggesting that these populations are declining.

\section{Study sites}

A survey of a $50 \times 50 \mathrm{~km}$ area containing ironstone formations in southwestern Australia was conducted and 29 populations were located across the coastal plain (Figure 1; Gibson et al., 2012). Two groups of four populations were selected for the study occurring some $19 \mathrm{~km}$ apart. The sizes of populations ranged from 3 to $>10000$ individuals but the majority consisted of $<150$ individuals, and were confined to road verges that are highly degraded. Comprehensive surveys failed to locate any further populations, but they are likely to have been more widespread prior to clearing within the confines of the discrete patches of ironstone soils.

\section{Plant sampling}

To assess genetic diversity, leaf material was collected from 160 adult plants, 20 in each of eight populations representing the geographic range of ssp. teretifolius (Figure 1; Table 1). To estimate mating system parameters and contemporary pollen-mediated gene immigration (henceforth termed pollen immigration), one population representing the intact landscape context (henceforth termed intact remnant) and two populations representing the degraded landscape (degraded remnant) were selected. Seed capsules were collected from 10 randomly selected plants in Doyle, Hairpin and Tutanup. Family mating system parameters for these plants were calculated within populations as replicates representing the intact $(n=10)$ and degraded landscapes $(n=10+10)$. Capsules were collected from the most terminal position on branches and therefore represented seed produced in the previous season. Capsules were desiccated in a drying oven $\left(27^{\circ} \mathrm{C}\right)$ and seeds were germinated and grown in a glasshouse for 1 month before tissue was harvested for DNA extraction.

The intact remnant Tutanup was a population of 80 individuals within a long $(11 \mathrm{~km})$ intact linear remnant that connects with other ssp. teretifolius populations through uncleared vegetation. The distances to the nearest patches of the study species within the remnant were $500 \mathrm{~m}$ to the west and $3.7 \mathrm{~km}$ to the east. The area between the known patches of C. quadrifidus ssp. teretifolius was thoroughly searched and no other individuals were found. The two degraded remnants at Doyle (44 individuals) and Hairpin (115 individuals) were linear, roadside remnants dominated by weeds with little or no surrounding natural vegetation. The Hairpin population consisted of three groups of plants spread over $70 \mathrm{~m}$. The Doyle remnant was a dense, continuous, linear group of plants with intertwined branches spread over $100 \mathrm{~m}$.

Leaf tissue was collected from all adult plants in mating system/pollen immigration study populations to genotype all candidate male parents within 


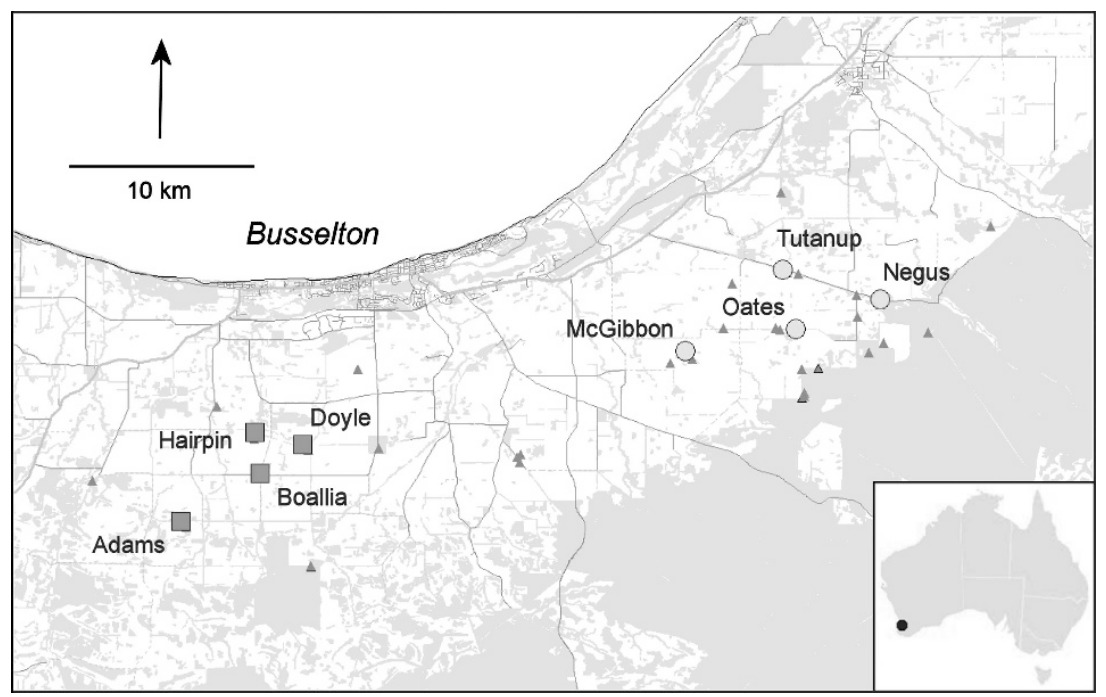

Figure 1 The distribution of Calothamnus quadrifidus ssp. teretifolius populations in south-western Western Australia. Squares and circles indicate sampled populations (west and east, respectively) and triangles indicate all other extant populations. Shaded areas show uncleared natural vegetation. A full color version of this figure is available at the Heredity journal online.

Table 1 Genetic diversity of sampled populations of Calothamnus quadrifidus ssp. teretifolius

\begin{tabular}{|c|c|c|c|c|c|c|c|c|}
\hline Population & Code & Total $N_{\text {adults }}$ & $N_{\mathrm{a}}$ (s.e.) & $p(1)$ (s.e.) & $H_{0}$ (s.e.) & $U H_{\mathrm{e}}$ (s.e.) & $F_{I S}(\text { s.e. })^{\mathrm{a}}$ & Bottleneck test \\
\hline \multicolumn{9}{|l|}{ Degraded } \\
\hline Oates & 0 & 344 & $5.11(1.09)$ & $0.26(0.14)$ & $0.433(0.100)$ & $0.523(0.133)$ & $0.031(0.032)$ & 0.902 \\
\hline McGibbon & M & 123 & $4.55(0.71)$ & $0.71(0.23)$ & $0.477(0.081)$ & $0.582(0.076)$ & $0.019(0.025)$ & 0.875 \\
\hline Boallia & $\mathrm{B}$ & 45 & $1.78(0.22)$ & $0.23(0.15)$ & $0.258(0.069)$ & $0.340(0.087)$ & $0.041(0.046)$ & 0.008 \\
\hline Doyle & D & 44 & $2.60(0.31)$ & $0.13(0.11)$ & $0.297(0.076)$ & $0.418(0.069)$ & $0.063(0.058)$ & 0.422 \\
\hline Hairpin & $\mathrm{H}$ & 115 & $4.35(0.67)$ & $0.15(0.13)$ & $0.481(0.090)$ & $0.622(0.087)$ & $0.031(0.032)$ & 0.014 \\
\hline Ambergate $^{c}$ & AM & 64 & & & & & & \\
\hline Mean (s.e.) & & & $3.68(0.63)$ & $0.30(0.11)$ & $0.389(0.047)$ & $0.497(0.052)$ & & \\
\hline \multicolumn{9}{|l|}{ Intact } \\
\hline Adams & A & 105 & $4.53(0.77)$ & $0.53(0.29)$ & $0.560(0.080)$ & $0.585(0.085)$ & $0.017(0.020)$ & 0.578 \\
\hline Negus & $\mathrm{N}$ & $10000+$ & $5.30(1.03)$ & $0.76(0.27)$ & $0.473(0.475)$ & $0.567(0.081)$ & $0.023(0.026)$ & 0.976 \\
\hline Tutanup & $\mathrm{T}$ & 80 & $4.01(0.64)$ & $0.54(0.23)$ & $0.450(0.104)$ & $0.475(0.103)$ & $0.015(0.017)$ & 0.990 \\
\hline Mean (s.e.) & & & $4.61(0.38)$ & $0.61(0.08)$ & $0.493(0.032)$ & $0.542(0.034)$ & & \\
\hline Total mean (s.e.) & & & $4.03(0.43)$ & $0.41(0.09)$ & $0.428(0.031)$ & $0.514(0.032)$ & & \\
\hline
\end{tabular}

Abbreviations: $H_{0}$, observed heterozygosity; $N_{\mathrm{a}}$, mean number of different alleles per locus; $p(1)$, number of private alleles; total $N_{\text {adults, }}$ total number of adult plants in the population; $U H_{\mathrm{e}}$, unbiased expected heterozygosity $(2 N /(2 N-1))^{*} H_{\mathrm{e}}$

aEstimated using the IMM method of Chybicki and Burczyk (2009).

bProbability of heterozygote excess, see materials and methods.

cArtificial planted population, collected only to provide background allele frequencies for pollen immigration analyses, see materials and methods.

populations. Accurate spatial locations could not be obtained for all plants in these populations because multi-stemmed plants often formed large, interleaved, dense clumps. Estimates of allele frequencies in the background pollen pool are required for some paternity analyses. To estimate these frequencies, leaf tissue was also collected from adults in remnants surrounding the three study sites. All plants were sampled in the remnants around Hairpin and Doyle (Ambergate, Boallia) because they were small enough. The Ambergate population is an artificial, planted population and was included only in background allele frequency estimation. Populations were much larger around Tutanup and complete sampling was not practicable. Twenty plants were sampled for background frequencies from remnants within $7 \mathrm{~km}$ of the study population (Negus, Oates).

\section{DNA isolation and microsatellite genotyping}

Adult plant DNA was extracted from $120 \mathrm{mg}$ of frozen leaf material per plant using Qiagen DNeasy plant mini extraction kits. Seedling DNA was extracted from $120 \mathrm{mg}$ of leaf tissue per individual using a scaled-down version of the CTAB method (Elliot and Byrne, 2005). Adult DNA samples collected to study genetic diversity were surveyed for nine microsatellite loci (CQ 1.7, CQ 1.10, CQ 2.12, CQ 5.11, CQ 6.1, CQ 6.7, CQ 7.5, CQ 4.1 and CQ 4.3) using primer pairs and PCR protocols described in the study by Elliot and Byrne (2005). Amplification products were separated on an Applied Biosystems 3730 capillary sequencer using a LIZ $500(-250)$ size standard. Bins were set and genotypes were scored manually using GENEMAPPER version 4.0 (Applied Biosystems, Foster City, CA, USA). Samples for which loci failed to amplify or where progeny genotypes were inconsistent with maternal genotypes were repeated.

To describe genetic diversity, nine microsatellite loci were analyzed in adult tissue. To estimate mating system parameters and pollen immigration in the three pollen immigration study sites, six of these loci that had suitable levels of polymorphism were surveyed in all adult plants, in 15 seedlings per seed parent in Doyle and Hairpin, in 20 seedlings per seed parent in Tutanup and in adults sampled for background allele frequencies (see Table 2; Supplementary Table S1). 
Table 2 Mean multilocus genetic diversity estimates, based on the six loci used for mating system and pollen-mediated gene immigration estimates, for all adult Calothamnus quadrifidus ssp. teretifolius plants in populations for which pollen-mediated gene immigration was estimated

\begin{tabular}{lrcccccc}
\hline Population & $N$ & $A_{\text {back }}$ & $A_{\text {local }}$ & $H_{0}$ & $H_{\mathrm{e}}$ & $f_{0}$ & $F_{\mathrm{IS}}{ }^{a}$ \\
\hline Doyle & 44 & $11.8(\mathrm{~B}, \mathrm{H}, \mathrm{AM})$ & 3 & 0.399 & 0.469 & 0.076 & $0.066(0.042)$ \\
Hairpin & 115 & $10.8(\mathrm{~B}, \mathrm{D}, \mathrm{AM})$ & 5.5 & 0.485 & 0.656 & 0.057 & $0.136(0.033)^{*}$ \\
Tutanup & 80 & $7.3(\mathrm{~N}, \mathrm{O})$ & 5.5 & 0.367 & 0.440 & 0.082 & $0.015(0.018)$
\end{tabular}

Abbreviations: $A_{\text {back }}$, mean number of alleles per locus observed in the background populations, see Table 1 for population codes; $A_{\text {local }}$, mean number of alleles per locus observed in the local population: $f_{0}$, estimated null allele frequency based on the IMM method of Chybicki and

Burczyk (2009); $H_{0}$, observed proportion of heterozygotes; $H_{\mathrm{e}}$, unbiased expected proportion of heterozygotes; $N$, number of adult plants genotyped

Standard error in parentheses; ${ }^{*} P<0.05$

aEstimated using the IMM method of Chybicki and Burczyk (2009)

\section{Data analyses}

Composite genotypic disequilibrium was calculated for adult plants within each population using GENEPOP 4.1 (Rousset, 2008) and a Bonferroni adjustment. Overall, significant composite genotypic disequilibrium was detected in two of 36 locus pair combinations (CQ 4.1 and CQ 1.1, CQ 7.5 and CQ 5.11). Significant disequilibrium for each of these locus combinations was found in one population but there was no consistent pattern across populations so it is unlikely to indicate chromosomal linkage. Estimates of the frequencies of null allele in adult plants sampled for genetic diversity were made using the individual inbreeding model method and the computer program INEST 1.0, which accounts for significant inbreeding (Chybicki and Burczyk, 2009). Estimates were significant $(P<0.05)$ in 7 of 72 locus/ population combinations; CQ 4.3 in Boallia, Doyle, Hairpin and McGibbon, CQ 7.5 in Tutanup and Oats, and CQ 1.7 in Hairpin. Null alleles can have a significant impact on differentiation estimates. To test whether this was the case in ssp. teretifolius, differentiation estimates were evaluated using the ENA method proposed by Chapuis and Estoup (2007) and the program FreeNA. $F_{\text {st }}$ values were not significantly different in raw and corrected data sets, showing that differentiation values were not affected by null alleles. Therefore, all loci were retained for genetic diversity analyses.

Genetic diversity. The numbers of alleles per locus $\left(N_{\mathrm{a}}\right)$ and the frequencies of private alleles $(p(1))$ were estimated using rarefaction and the program HPRare 1.0 (Kalinowski, 2005) to account for unequal sample sizes caused by null alleles/missing data. The smallest sample size for this data set was $n=16$. Observed and expected heterozygosities $\left(H_{\mathrm{o}}\right.$ and $\left.H_{\mathrm{e}}\right)$ were estimated using GENALEX V6.4 (Peakall and Smouse, 2006). To test the hypothesis that that there is no significant difference in the level of genetic diversity between the intact and degraded populations, population multilocus means were compared using $t$-tests. To detect recent population bottlenecks, we used 1000 replicates and the Wilcox sign-rank test of heterozygosity of excess under the two-phase model in the program BOTTLENECK 1.2.02 (Piry et al., 1999).

Differentiation and gene flow among populations. Multilocus pairwise differentiation of populations $\left(F_{\mathrm{ST}}\right)$ was calculated using ARLEQUIN V3.11 (Excoffier et al., 2005) with significance tested by 10000 permutations. The genetic divergence index $\left(D_{\text {est }}\right)$, proposed by Jost $(2008)$ as a truer representation of differentiation that is not confounded by within-population diversity, was also estimated. Genetic distances between populations, based on CS Chord genetic distance, were calculated using POWERMARKER V3.0 (Liu and Muse, 2005) and illustrated by a consensus neighbor-joining tree constructed from 1000 bootstrap replicates using the CONSENSE program in PHYLIP 3.69 (Felsenstein, 1989). Genetic structure was also examined using Bayesian model-based clustering employing the procedure implemented in the program STRUCTURE 2.3.3 (Pritchard, Stephens and Donnelly, 2000). The STRUCTURE program was run using no prior knowledge and the admixture ancestry model. The Markov chain Monte Carlo parameters were set to a burn-in of 150000 with $10^{6}$ iterations. The optimum $K$, indicating the number of true clusters in the data, was determined from 20 replicate runs for each value of $K \varepsilon\{1, \ldots, 12\}$ using the ad hoc statistic $\Delta K$ from the program STRUCTURE HARVESTER V0.6.93 (Earl and von Holdt, 2012). Similarity among different runs was assessed using the similarity coefficient $h^{\prime}$ from the computer program CLUMPP 1.1.2 (Jakobsson and Rosenberg, 2007).

Differentiation of populations was also described by a hierarchical analysis of molecular variance using ARLEQUIN V3.11 (Excoffier et al., 2005) and tested with 10000 permutations. Mantel tests for a linear correlation between pairwise genetic distances and the logarithms of geographical distance between populations were carried out using GENALEX V6.4 (Peakall and Smouse, 2006) and tested by 10000 random permutations.

To test whether gene flow between populations has changed significantly since fragmentation, we estimated historical and recent (within the last few generations) gene flow to compare with estimates of contemporary pollenmediated gene immigration. Long-term historical (equilibrium) estimates of mutation-scaled population sizes $(\Theta)$ and effective immigration rates $\left(M_{\mathrm{ij}}\right.$; from population $i$ to population $j$ ) were inferred from the genotypes of adult plants sampled in eight populations using the $n$-coalescent and Bayesian inference approach implemented in the software MIGRATE-N v3.3.2 (Beerli, 2006, 2009). A Brownian process was used to model microsatellite mutation. We ran 10 replicates of MIGRATE-N using a Markov chain Monte Carlo search of 10000 burn-in steps followed by 20000 steps with parameters recorded every 100 steps; a static heating scheme with temperatures $(1.0,1.5$, $\left.3.0,1 \times 10^{6}\right)$; uniform prior on theta (min: 0.0 , max: 100.0, delta: 10.0 ); uniform prior on migration (min: 0.0, max: 1000.0, delta: 100.0), with parameter values starting from $F_{\mathrm{ST}}$-based estimates. More recent effective gene flow, measured as putative first-generation migrants, was also estimated using the L_home test statistic in GENECLASS 2.0 (Piry et al., 2004), which was chosen as it could not be established with certainty that all potential sources of pollen had been sampled. Likelihoods were computed using Bayesian and Markov chain Monte Carlo methods with 10000 simulated individuals at a threshold of 0.01 .

Mating system. To compare levels of inbreeding and the diversity of mating events for families in degraded and intact remnants, parentage and sibship was inferred among arrays of progeny from 10 seed parents in Doyle, Hairpin and Tutanup populations using the full-pedigree likelihood methods implemented in the program COLONY 2.0 (Jones and Wang, 2010). This method of parentage analysis has been shown to perform well when there are $<20$ polymorphic loci and incomplete sampling of all potential parents, as is the case for many studies of natural populations (Harrison et al., 2013). It is more powerful than methods where pairs of progeny are the unit of observation as it infers the entire multilocus pedigree, is little affected by mutation and inbreeding, and takes genotyping errors into account (Wang and Santure, 2009; Jones and Wang, 2010). Analysis parameters were set for polygamy, inbreeding, monoecy, a large run, full likelihood and updated allele frequencies. Genotyping errors estimated for adults in each remnant using the program Nm +1.1 (Chybicki and Burczyk, 2010) were included. Loci with genotype error frequencies greater that 0.1 were excluded from the analyses (CQ 4.3 in Hairpin). Correlated outcross paternal diversity ( $\left.c p_{\text {div }}\right)$ was calculated as the mean proportion over seed parents of outcrossed progeny that are full siblings where the proportion for each seed parent was adjusted by dividing by the number of pollen parents identified among the full siblings. Comparisons of parameters among families from intact and degraded remnants were done by analysis of variance. Intact and degraded remnants were compared with single degree-of-freedom contrasts.

To determine whether inbreeding was due to selfing and/or mating between genetically similar individuals (relatives), we also made population estimates of biparental inbreeding from the difference between single $\left(s_{\mathrm{s}}\right)$ and multilocus $\left(s_{\mathrm{m}}\right)$ estimates of selfing using the correlated matings model and the program MLTR 3.4 (Ritland, 2002). To compare with $c p_{\text {div }}$ estimates based on COLONY 2.0 analyses, we also used MLTR 3.4 to calculate population estimates of the correlation of paternity between outcrossed sibling pairs $\left(r_{\mathrm{p}}\right)$ as a measure of the fraction that share the same male parent. Pollen and ovule gene frequencies were estimated separately. Standard errors were based on 1000 bootstraps. Inbreeding coefficients were also estimated for adult plants using the individual 
inbreeding model method and the computer program INEST 1.0 described in the study by Chybicki and Burczyk (2009).

Estimating pollen immigration by paternity analyses. Genotyping errors and incomplete sampling of potential male parents have been problematic in paternity analyses (Oddou-Muratorio and Klein, 2008). To address this, we used more than one method of estimation and analytic methods developed recently to take genotyping errors into account as part of estimation procedures (Chybicki and Burkzyk, 2009; Slavov et al., 2009; Jones and Wang, 2010).

Paternity exclusion was performed using six loci and the program PFL, and the paternity exclusion with mismatches method is described in detail by Slavov et al. (2009). Multilocus genotyping error rates in progeny were low in the remnants examined here (Doyle 2.0\%; Hairpin 3.9\%; Tutanup 2.9\%; see Supplementary Table S1) and within the limits used previously for paternity exclusion allowing for mismatches (Slavov et al., 2009); therefore, all loci were retained for analysis. To maintain the detection probability (d) above the recommended 0.8 , one mismatch was possible in this study. Simulations predict bias at this level to be relatively low (Slavov et al., 2009). The numbers of alleles per locus $\left(N_{\mathrm{a}}\right)$ in the background populations were estimated using rarefaction to account for differences in sample size, and the program HP-Rare 1.0 (Kalinowski, 2005).

The neighborhood model implemented in the program $\mathrm{Nm}+1.1$ (Chybicki and Burczyk, 2010) was also used to estimate pollen immigration. This approach has the advantage of jointly estimating pollen gene flow with background allele frequencies, avoiding the significant bias that can be introduced by inaccurate estimation of background allele frequencies. Analyses were initially done using all loci and then repeated excluding loci with genotypic error frequencies of $>0.1$ (Hairpin, CQ4.3). The precision of convergence was set at 0.001 .

Estimates of pollen immigration were also made separately for each population from the proportion of progeny for which no male parent could be identified within the population, using the full-pedigree likelihood method in COLONY 2.0 (Jones and Wang, 2010) and the same parameters used for mating system parameters (see above).

\section{RESULTS}

Genetic diversity, differentiation and gene flow among populations Overall levels of mean population diversity were moderate in ssp. teretifolius $\left(N_{\mathrm{a}}=4.03, H_{\mathrm{o}}=0.428, U H_{\mathrm{e}}=0.514\right.$; Table 1$)$. The number of alleles per locus varied from 3 to $20($ mean $=11.3)$ and there were 102 alleles among the 160 adult individuals sampled over the species' geographic distribution (see Supplementary Table S2). Levels of diversity within populations were similar in all populations except for the small, degraded remnants at Boallia and Doyle, where values were lower. Overall, there was no significant difference between degraded and intact remnants for any measure of diversity ( $t$-tests, $P>0.08)$. However, significant probabilities of heterozygote excess were found in the degraded remnants Boallia and Hairpin $(P<0.01$ and $P<0.05$ respectively; Table 1$)$, suggesting they have experienced genetic bottlenecks. Inbreeding coefficients $\left(F_{\text {IS }}\right)$ of adults were not significantly different from zero in any population but the sample size was low. Positive values may have been masked by high standard errors due to sample size alone.

Population differentiation was significant, as indicated by overall $F_{\mathrm{ST}}$ and $D_{\text {est }}$ indices $(0.277$ and $0.421, P<0.05)$. The pairwise population $F_{\mathrm{ST}}$ estimates were also all significant (see Supplementary Table S3). Both the lowest (Oats and McGibbon; 0.119 and 0.11) and highest (Adams and Boallia; 0.525 and 0.407) pairwise $F_{\mathrm{ST}}$ and $D_{\text {est }}$ values were between geographically close populations. The analysis of variance showed that there was significant differentiation of eastern and western populations although the majority of diversity was among populations within locations (east and west) rather than among geographical locations (Table 3).
Table 3 Analysis of molecular variance (AMOVA) for Calothamnus quadrifidus ssp. teretifolius

\begin{tabular}{|c|c|c|c|c|c|}
\hline Grouping & Source of variation & d. $f$. & $\begin{array}{c}\text { Variance } \\
\text { components }\end{array}$ & $\begin{array}{c}\text { Variance } \\
\text { (\%) }\end{array}$ & $\begin{array}{l}\text { Fixation } \\
\text { indices }\end{array}$ \\
\hline \multirow{2}{*}{$\begin{array}{l}\text { Species/ } \\
\text { populations }\end{array}$} & Among populations & 7 & $0.758 \mathrm{~V}^{\mathrm{a}}$ & 27.70 & $F_{\mathrm{ST}}=0.277^{*}$ \\
\hline & Within populations & 312 & $1.977 \mathrm{~V}^{\mathrm{b}}$ & 72.30 & \\
\hline \multirow[t]{3}{*}{$\begin{array}{l}\text { Species/location/ } \\
\text { population }\end{array}$} & $\begin{array}{l}\text { Among locations } \\
\text { (east/west) }\end{array}$ & 1 & $0.192 \mathrm{~V}^{\mathrm{a}}$ & 6.8 & $F_{\mathrm{CT}}=0.160^{*}$ \\
\hline & $\begin{array}{l}\text { Among populations } \\
\text { within locations }\end{array}$ & 6 & $0.648 \mathrm{~V}^{b}$ & 23.01 & $F_{\mathrm{SC}}=0.247^{*}$ \\
\hline & Within populations & 312 & $1.977 \mathrm{Vc}^{\mathrm{c}}$ & 70.19 & \\
\hline
\end{tabular}

${ }^{*} P<0.05$, the probability of obtaining by chance a $F_{\mathrm{ST}}$ (or $F_{\mathrm{CT}}$ or $F_{\mathrm{SC}}$ ) value equal to or greater than the observed value, estimated from 10000 permutations.

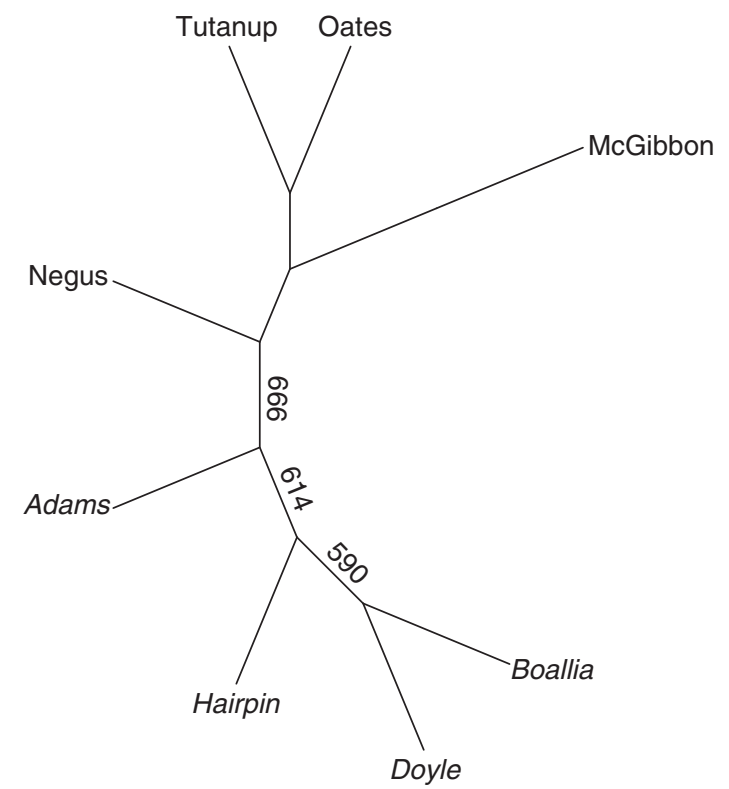

Figure 2 Neighbor-joining tree of CS Chord genetic distance (Cavalli-Sforza and Edwards, 1967) between populations of Calothamnus quadrifidus ssp. teretifolius. Bootstrap support $>50 \%$ is shown on branches as number of bootstraps/1000. Names of western remnants are italicized.

This lack of strong association of differentiation with location was also reflected in the neighbor-joining tree of genetic distance (Figure 2). East and west populations were separated in $67 \%$ of replicates but there was not strong support for any grouping within these two clusters. This pattern is again reflected in a significant but weak linear correlation between CS Chord genetic distance and geographic distance (Mantel's $r=0.528, P<0.05$ ). Bayesian analysis using STRUCTURE differentiated 10 clusters (Figure 3 ) with a clear peak in the value of $\Delta K$ at $K=10$ and strong similarity of 20 replicate runs $\left(h^{\prime}=0.99\right)$. Consistent with the significant differentiation of populations observed, all populations except Oats mainly comprised individuals with ancestry from different clusters. Oats and Negus had substantial proportions of their ancestry $(q>0.3)$ in a shared cluster $\left(q_{7}\right)$ and substantial proportions of admixed individuals. Only Oats had significant proportions $(q>0.05)$ of population ancestry shared with more than one other population, from the other eastern populations McGibbon $\left(q_{1}=0.059\right)$, Tutanup $\left(q_{3}=0.059\right)$ and Negus 


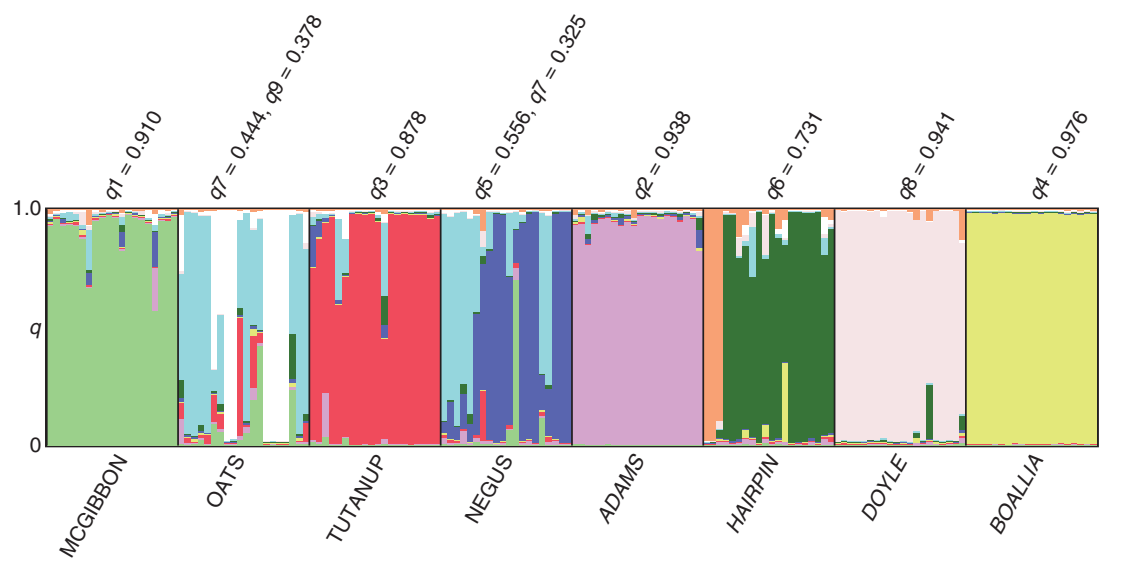

Figure 3 Genetic ancestry of Calothamnus quadrifidus ssp. teretifolius from eight populations estimated using STRUCTURE 2.3.3. Each individual's genome is shown as a thin line divided into shaded segments in proportion to the estimated ancestry in each cluster $\left(q_{n}\right)$. Clusters are shown as different colors. The proportion of estimated ancestry in the majority cluster(s) for each population is shown above the plot. The results shown are the optimal alignment of 20 replicates. Names of western remnants are italicized.

Table 4 Estimates of mating system parameters based on full-pedigree likelihood methods implemented in COLONY 2.0 and the correlated mating model implemented in MLTR 3.4 for populations of Calothamnus quadrifidus ssp. teretifolius

\begin{tabular}{|c|c|c|c|c|c|c|c|}
\hline Population & $s^{\mathrm{a}}$ & $s_{\mathrm{s}-} s_{\mathrm{m}}{ }^{\mathrm{b}}$ & $N_{\mathrm{p}}^{\mathrm{a}}$ & $c p_{\text {div }}{ }^{a}$ & $F S_{\text {outcross }}{ }^{a}$ & $N_{\mathrm{e}}^{\mathrm{a}}$ & $r_{\mathrm{p}}^{\mathrm{b}}$ \\
\hline Doyle & $0.453(0.360-0.547)$ & $0.093(0.082)$ & $2.4(0.4)$ & $0.49(0.12)$ & $0.46(0.13)$ & $13(7-30)$ & $0.22(0.07)$ \\
\hline Hairpin & $0.687(0.604-0.769)$ & $0.111(0.070)$ & $3.0(0.5)$ & $0.26(0.09)$ & $0.16(0.06)$ & $15(8-30)$ & $0.63(0.26)$ \\
\hline
\end{tabular}

Abbreviations: $c p_{\text {divv }}$, mean proportion of outcrossed progeny per seed parent that are full siblings divided by the number of pollen parents identified among the outcrossed full siblings; $F S_{\text {outcross }}$, mean proportion of outcrossed full siblings per seed parent; $N_{e}$, effective population size, assuming non-random mating; $N_{\mathrm{p}}$, mean number of outcross pollen parents per seed parent; $r_{\mathrm{p}}$, multilocus correlation of outcrossed paternity; $s$, selfing rate $(95 \% \mathrm{Cl}) ; s_{s}-s_{m}$ estimate of biparental mating as the difference between single- and multi-locus selfing rates from MLTR 3.4 (Ritland, 2002)

Standard errors in parentheses; ${ }^{*} P<0.05$.

aparameters estimated using COLONY 2.0 (Jones and Wang, 2010).

bParameters estimated using MLTR 3.4 (Ritland, 2002).

$\left(q_{7}=0.444\right)$. This pattern was consistent with the weak association of genetic and geographic distances observed and the weak east/west grouping of populations in the neighbor-joining tree. Most individuals in other populations were not admixed with ancestry predominantly from one (McGibbon, Tutanup, Adams, Doyle, Boallia) or two (Hairpin) clusters. As expected for a population that has experienced a bottleneck, Boallia had a very high proportion of ancestry in all individuals from one cluster.

Theoretically, inter-population genetic divergence will increase due to random genetic drift, particularly when population sizes and gene flow are such that $N_{\mathrm{em}}<1$ (Wright, 1951). This threshold is considered too low by some authors who suggest a level below which divergence is likely to be significant of $N_{\mathrm{em}}<10$ migrants per generation (Wang, 2004). By either criterion, historical levels of the number of immigrants per generation for populations of ssp. teretifolius estimated with MIGRATE-N were low (mean $4 N_{\mathrm{m}}=0.546$, range $\left.0.316-1.218\right)$. Estimates of long-term mutationscaled migration between populations $\left(M_{\mathrm{ij}}\right)$ are given in Supplementary Table S4. When expressed as the number of immigrants per generation $(x N m=\Theta M)$, the mean estimate was lower among western populations (0.428) than eastern ones (0.682), and higher from west to east (0.661) than from east to west (0.390), but all estimates were low. These findings were consistent with the GENECLASS 2.0 (Piry et al., 2004) analysis that detected seven firstgeneration migrants in the sampled populations. One first-generation migrant was found using the L-home statistic in every population except the degraded remnants Boallia and Hairpin. This test statistic tends to estimate the upper limit of migration.

\section{Mating system}

There was significant inbreeding in both degraded and intact remnants and the majority was due to selfing rather than biparental inbreeding $(s=0.453-0.687$; Table 4$)$. The inbreeding coefficient was significantly positive in Hairpin but this may be due to a Wahlund effect as the entire population was sampled $\left(F_{I S}=0.136(0.033)\right.$, $P<0.05$; Supplementary Table S5). The only significant difference between remnants was that the inbreeding in Doyle was lower than that of the other larger, degraded remnant Hairpin. Inbreeding in Doyle was not significantly lower than that of the intact remnant. There were small amounts of biparental mating in all remnants but it was significant only in the intact remnant. Comparison of mating parameters $\left(s, N_{\mathrm{p}}, c p_{\text {div }}\right.$ and $F S_{\text {outcross }}$ ) for families by analysis of variance showed no overall significant differences between populations $\left(s, F_{2,29}=1.24, P=0.306 ; N_{\mathrm{p}}, F_{2,29}=0.58, P=0.566 ; c p_{\text {div }}\right.$, $\left.F_{2,27}=2.22, P=0.129 ; F S_{\text {outcross }}, F_{2,29}=2.07, P=0.146\right)$. The single degree-of-freedom contrast testing comparing intact and degraded remnants also showed no significant differences $(s, t=0.15, P=0.881$; $N_{\mathrm{p}}, t=-0.52, P=0.605 ; c p_{\text {div }}, t=1.21, P=0.237 ; F S_{\text {outcross }}, t=0.27$, $P=0.793)$.

When population estimates were examined, there were large proportions of full siblings among progeny in all remnants (Table 4). The two degraded remnants had the highest (Doyle 
$\left.F S_{\text {outcross }}=0.46\right)$ and lowest (Hairpin $F S_{\text {outcross }}=0.16$ ) proportions but again the differences between all the remnants were not significant. From the COLONY 2.0 analyses, the number of outcross pollen parents per seed parent ranged between zero and seven (data not shown) with a mean of 2.7 for degraded remnants compared with 4.0 for the intact remnant (Table 4). The outcrossed correlated paternal diversity estimates $\left(c p_{\text {div }}\right)$ indicated significant correlation in all remnants. However, although higher for one degraded remnant (Doyle $c p_{\text {div }}=0.49$ ), the differences between the remnants and between the degraded versus the intact remnant were not significant. The MLTR 3.4 analyses also showed significant correlation of paternity in all populations $\left(r_{\mathrm{p}}>0, P<0.05\right.$; Table 4$)$. The estimate for Hairpin was larger than other populations $\left(r_{\mathrm{p}}=0.63 \pm 0.51\right)$ but the standard error was also large and the differences between intact and degraded remnants were not significant. Overall, there was no significant evidence of greater mating diversity in the intact remnant when compared with degraded remnants.

\section{Paternity analyses and contemporary pollen immigration}

Estimates of pollen immigration were low in all populations for all three estimation methods and there was no significant difference between degraded and intact remnants (0-14.7\%; Table 5). The approach used in this study improves confidence in this finding because the combination of analysis methods addressed the issues of genotyping errors and incomplete sampling of candidate pollen parents that have been problematic in pollen immigration estimates. For paternity exclusion, theoretical paternity exclusion probabilities (local and background combined) were high in both the western and eastern populations $(0.986,0.941$ respectively). We were not able to apply conservative ( $>1$ mismatch) adjustments for mistyping errors while maintaining high detection probabilities $(d>0.8)$. This may cause estimates of pollen immigration to be biased upwards. However, relatively unbiased estimates were possible as mistyping error rates

Table 5 Estimates of pollen immigration using paternity exclusion with mismatches, the neighborhood model, and full-pedigree likelihood methods, in three Calothamnus quadrifidus ssp. teretifolius populations with different ecological contexts

\begin{tabular}{|c|c|c|c|c|}
\hline & \multirow[t]{2}{*}{ Parameter } & \multicolumn{3}{|c|}{ Population } \\
\hline & & Doyle & Hairpin & Tutanup \\
\hline \multirow[t]{4}{*}{$\begin{array}{l}\text { Paternity } \\
\text { exclusion }\end{array}$} & $\begin{array}{l}\text { Background } \\
\text { frequencies }^{b}\end{array}$ & $\mathrm{~B}, \mathrm{H}, \mathrm{AM}$ & $\mathrm{B}, \mathrm{D}, \mathrm{AM}$ & $\mathrm{N}, \mathrm{O}$ \\
\hline & $b$ & $0.098(0.034)$ & $0.079(0.039)$ & $0.140(0.039)$ \\
\hline & $d$ & $0.971(0.0002)$ & $0.918(0.003)$ & $0.953(0.0002)$ \\
\hline & $\begin{array}{l}\% \text { pollen } \\
\text { immigration }(m)\end{array}$ & $10.1(3.5)$ & $8.7(4.3)$ & $14.7(4.1)$ \\
\hline \multirow[t]{2}{*}{$\begin{array}{l}\text { Neighborhood } \\
\text { modelc }^{c}\end{array}$} & $\begin{array}{l}\text { Selfing rate } \\
\left(P_{\text {selfing }}\right)\end{array}$ & $0.666(0.052)$ & $0.833(0.026)$ & $0.730(0.039)$ \\
\hline & $\begin{array}{l}\% \text { pollen } \\
\text { immigration } \\
\left(P_{\text {outside }}\right)\end{array}$ & $7.5(5.2)$ & $0(7.8)$ & $11.9(6.0)$ \\
\hline $\begin{array}{l}\text { Full-pedigree } \\
\text { method }^{\text {d }}\end{array}$ & $\begin{array}{l}\% \text { pollen } \\
\text { immigration }\end{array}$ & 0 & 8.7 & 5.8 \\
\hline \multicolumn{5}{|c|}{$\begin{array}{l}\text { Abbreviations: } b \text {, observed proportion of pollen immigrants; } d \text { detection probability; } m \text { Estimate } \\
\text { of pollen immigration adjusted for cryptic gene flow }(b / d) ; P_{\text {selfing, }} \text { proportion of seedlings from } \\
\text { self-pollination; } P_{\text {outside, proportion of seedlings pollinated by plants outside the populations }} \\
\text { Standard errors in parentheses } \\
\text { aAfter the method of Slavov et al. (2009). } \\
\text { b Local background pollen allele frequencies, see Table } 1 \text { for population codes. } \\
\text { cAfter the method of Chybicki and Burczyk (2010). } \\
\text { dAfter the method of Jones and Wang (2010). }\end{array}$} \\
\hline
\end{tabular}

were low and the allelic diversities of likely pollen source populations were moderate (Supplementary Table S5). High population differentiation is also expected to increase the probability of distinguishing immigrant pollen from local pollen and limiting the extent of cryptic gene flow. Pollen immigration estimates made using $\mathrm{NM}^{+}$and COLONY 2.0 were also low in all populations (Table 5). Values were not significantly different from those estimated by paternity exclusion. Low pollen immigration for the intact population was also consistent with predictions based on historical immigration levels.

Using $\mathrm{NM}^{+}$estimates, the majority of pollen in outcrossed mating events came from plants within an individual seed parent's population (Doyle, 77.5\%; Hairpin, 100\%; Tutanup, 55.9\%; mean 74.8\%). Results from the COLONY 2.0 analysis for Hairpin showed three seed parents where the inferred genotype of the pollen parent of some 'immigrant' progeny was the same in each case, suggesting it was from one source. Similarly, in Tutanup, five seed parents had progeny from immigrant pollen where the inferred genotype of the pollen parent was the same.

\section{DISCUSSION}

The level and pattern of different ancestry and genetic differentiation of populations of ssp. teretifolius suggest that gene flow in the past was low and not sufficient to counteract the combined effects of substantial inbreeding and genetic drift and/or selection on populations. Against this background of low historical gene flow, there was no significant difference between the levels of contemporary pollenmediated gene immigration into degraded or intact remnants of C. quadrifidus ssp. teretifolius. This suggests that the historical pattern of connectivity has not been changed by fragmentation of the landscape over the past 110 years.

\section{Gene flow, population differentiation and pollen immigration}

The level and pattern of differentiation found among populations of ssp. teretifolius was consistent with predictions for an endemic species with a mixed-mating system, limited gene flow and spatial patchiness (Nybom, 2004; Duminil et al., 2009). Calothamnus quadrifidus ssp. teretifolius plants can live for $>50$ years, so there are likely to have been relatively few generations since human-induced fragmentation. The moderately high genetic differentiation and different ancestry among remnants over a small geographic range therefore suggests that genetic connectivity was restricted before the clearing that has occurred over the last 110 years. The comparatively higher proportion of genetic variance between populations rather than between geographic groupings of populations is also consistent with an evolutionary history of inbreeding, low gene flow and diversifying drift/ selection. Indeed, a similar pattern was found in the insular, island tree species Pterocarpus officinalis Jacq. (Muller et al., 2009) in which the genetic system was characterized by inbreeding, bottlenecks, high differentiation and low numbers of migrants per generation. The similarity of genetic patterns in the two species suggests that the ironstone habitats of ssp. teretifolius are functioning as terrestrial islands.

Contemporary pollen-mediated gene immigration in ssp. teretifolius was low but the presence of immigrant pollen in the disjunct populations indicates that pollinators can move pollen over both intact native vegetation and cleared farmland. The identification of one immigrant genotype as the likely pollen donor for the progeny of several seed parents within a population is consistent with a single pollinator visiting the population once and then moving between several plants in that visit. There was no clear and consistent evidence that contemporary pollen immigration into degraded remnants was 
significantly different from that into an intact remnant suggesting gene migration has not been significantly changed by fragmentation. Calothamnus quadrifidus ssp. teretifolius populations that were previously separated by woodland habitat that acted as a barrier to pollen migration between populations are now separated by cleared agricultural land that acts as a contemporary barrier.

Reported estimates of pollen immigration into populations of species with rare or naturally patchy populations range from low (4.3-16.5\%; Bittencourt and Sebbenn, 2007; Muller et al., 2009; Finger et al., 2011; Llorens et al., 2012) to high (43-77\%; OddouMuratorio and Klein, 2008; Lander et al., 2010). Reported changes in immigration levels in recently fragmented species include both increases (Byrne et al., 2007; Bacles and Jump, 2011) and decreases (Robledo-Arnuncio and Gill, 2005; Sebbenn et al., 2011). For ssp. teretifolius, genetic isolation of populations pre-dates fragmentation and the movement of pollen in the landscape does not appear to have been affected by changes in landscape characteristics. This suggests genetic connectivity is not the most pressing conservation issue for this species.

\section{Mating system and genetic diversity}

Significant inbreeding, predominantly from self-pollination, shows that ssp. teretifolius is self-compatible and that pollinators often visit flowers within the same plant. Low estimates of pollen immigration indicate that most pollinator movements were within remnants rather than between them. Although individual selfing and the number of pollen parents per seed parent did vary both within and between remnants, there was no consistent significant evidence that fragmentation has resulted in higher inbreeding or correlation of paternity in the degraded remnants.

High levels of inbreeding, such as those found in ssp. teretifolius, have been associated with inbreeding depression in plants, expressed as reduced reproduction and survival of seedlings (Young et al., 1996; Charlesworth and Willis, 2009). This does not appear to be the case in ssp. teretifolius where, despite high levels of selfing, plants in both degraded and intact remnants produced large amounts of viable seed (Gibson et al., 2012). As proposed for other rare, long-lived, selfcompatible species, ssp. teretifolius might be less prone to the effects of inbreeding following fragmentation. In this regard, C. quadrifidus ssp. teretifolius differs strongly from its cogener, ssp. quadrifidus. The latter common subspecies has a widespread range of $>188000 \mathrm{~km}^{2}$ and relatively high outcrossing rates that are consistent in different sized populations. However, seed production was inversely related to population size in ssp. quadrifidus (Yates et al., 2007), leading the authors to suggest that the genetic load, expressed as high seed abortion, masks higher selfing levels in small populations in this subspecies. The difference between the two taxa might be explained by purging of the genetic load in ssp. teretifolius as a result of a long history of inbreeding or from founder effects or extreme bottlenecks during the evolution of the subspecies (Gibson et al., 2012). Support for the hypothesis of purging of genetic load in small populations has also been found in other species (Angeloni et al., 2011).

The genetic diversity found in ssp. teretifolius was consistent with expectations for a mixed-mating species (Duminil et al., 2009). However, the lower diversity and the signature of genetic bottlenecks found in some degraded remnants indicate that ssp. teretifolius is experiencing some deleterious effects of fragmentation. Reduced diversity within populations following fragmentation has been found in several species (Honnay and Jacquemyn, 2007; Aguilar et al., 2008) but not all fragmentation events result in erosion of genetic diversity (Young et al., 1996; Aquilar et al., 2008; Severns et al., 2011; Wang et al., 2011). When fragmentation has caused changes, meta-analyses indicate large negative effects on allelic diversity and outcrossing rates, but non-significant overall effects on inbreeding coefficients measured in adults. This has been variously attributed to selection favoring heterozygous progeny (Coates et al., 2007), longevity and persistent long-distance gene flow (Aguilar et al., 2008). Indeed, the lack of consistent change in mating parameters led Wang et al. (2011) to conclude that inbreeding coefficients and selfing rates may have limited value as indicators of genetic changes following fragmentation.

In contrast to the predictions of reduced outcrossing in a selfcompatible species following fragmentation, estimates did not consistently indicate more inbreeding in degraded remnants. However, in contrast to many common, widespread species, ssp. teretifolius did have existing high levels of inbreeding from selfing, a small amount of biparental inbreeding, and correlation of outcrossed paternity, the latter arising from low numbers of pollen parents per seed parent. Correlated paternity is a form of inbreeding because when only a few plants provide most of the ovules or pollen for the next generation, progeny are subject to biased gene frequencies and increased levels of inbreeding. Correlation of paternity can be caused by variation in flowering phenology or the number of potential pollen sources, and/ or availability and behavior of pollinators. All of these are possible in ssp. teretifolius but the number of potential pollen sources within populations is unlikely to be limiting in any of the study sites. However, paternity analyses do indicate that pollinators may move between several plants within ssp. teretifolius remnants, depositing pollen from one source. Such behavior would give rise to correlation of paternity. Variable phenology and pollinator behavior could also account for the variation observed among selfing rates of individual plants. It has been suggested that the behavior of pollinators within remnants that are in good condition is likely to differ from that in degraded remnants where there are no other native species for pollinators to visit (Yates et al., 2007). In the common C. quadrifidus ssp. quadrifidus, increased correlation of paternity in degraded remnants was attributed to fewer pollinator movements and the effects of density and shape on within-population pollination (Byrne et al., 2007). In contrast to its sister taxon, populations of ssp. teretifolius in degraded remnants did not show significant increases in correlated paternity. This is most likely to reflect a difference in impact of fragmentation on predominantly outbred versus mixedmating species, although it may also reflect differences in the pollinators and/or their behavior in remnants of the two subspecies.

\section{Impacts of fragmentation}

The estimation of recent gene immigration is fundamental to a wide range of evolutionary and conservation studies (Robledo-Arnuncio et al., 2009; Bacles and Jump, 2011) because of concerns that fragmentation can lead to genetic isolation and reductions in diversity and evolutionary potential. Conservation strategies for some rare species have included genetic rescue through artificial crosses in species with low gene flow (Finger et al., 2011) but in others, genetic connectivity may not be a high conservation priority (Lander et al., 2010).

In ssp. teretifolius, inbreeding, historically low gene flow and diversifying drift/selection seem to have characterized its genetic system. Overall, diversity, mating system parameters and pollen immigration into degraded and intact remnants were similar but there is some evidence that sudden reductions in population size (genetic bottlenecks) have led to loss of diversity. Demographic studies (Gibson et al., 2012) found no recruitment in degraded populations of ssp. teretifolius but this appears to be directly related to 
the ecological impact of fragmentation where the high density of weeds restricts germination and establishment rather than to any shortage of viable seed resulting from the genetic impact of fragmentation. These populations will probably disappear as adult plants die. The genetic differentiation among ssp. teretifolius remnants indicates collections of seeds from these degraded remnants would therefore be important to conserve the diversity of the subspecies. For in situ conservation, it would be prudent to prioritize the conservation of populations where the associated native vegetation remains intact to maintain natural ecosystem processes and reduce the likelihood of loss of diversity and the human-induced distortion of the evolutionary potential of populations.

More generally, lessons from this study can be applied to other local endemics with strongly differentiated population structure, natural separation of populations and features of their genetics and ecology that counter the impacts of inbreeding. Our findings lend support to the proposal that rare, long-lived, self-compatible species may be less susceptible to the effects of fragmentation. As proposed by Hopper (2009), human-induced fragmentation of the broader matrix of intact vegetation may have little impact on naturally disjunct biota if their population systems remain intact and provided edge effects are minimal. If there has been no change in gene immigration between populations following fragmentation then, as in the view of Hobbs and Yates (2003), conservation efforts can prioritize management of key ecosystem processes and intact populations.

\section{DATA ARCHIVING}

Data deposited in the Dryad repository: doi:10.5061/dryad.dd550.

\section{CONFLICT OF INTEREST}

The authors declare no conflict of interest.

\section{ACKNOWLEDGEMENTS}

This research was supported by South West Catchment Council.

Aguilar R, Quesada M, Ashworth L, Herrerias-Diego Y, Lobo J (2008). Genetic consequences of habitat fragmentation in plant populations: susceptible signals in plant traits and methodological approaches. Mol Ecol 17: 5177-5188.

Angeloni F, Ouborg NJ, Leimu R (2011). Meta-analysis on the association of population size and life history with inbreeding depression in plants. Biol Conserv 144: 35-43.

Bacles CFE, Jump AS (2011). Taking a tree's perspective on forest fragmentation genetics. Trends Plant Sci 16: 13-18.

Beerli P (2006). Comparison of Bayesian and maximum-likelihood inference of population genetic parameters. Bioinformatics 22: 341-345.

Beerli P (2009). How to use MIGRATE or why are Markov chain Monte Carlo programs difficult to use? In: Bertorelle G, Bruford MW, Hauffe HC, Rizzoli A, Vernesi C (eds) Population Genetics for Animal Conservation. vol. 17 of Conservation Biology Cam bridge University Press: Cambridge, UK, pp 42-79.

Bittencourt JVM, Sebbenn A (2007). Patterns of pollen and seed dispersal in a small, fragmented population of the wind-pollinated tree Araucaria angustifolia in southern Brazil. Heredity 99: 580-591.

Byrne M, Elliott CP, Yates C, Coates DJ (2007). Extensive pollen dispersal in a bird pollinated shrub, Calothamnus quadrifidus, in a fragmented landscape. Mol Ecol 16: 1303-1314.

Cavalli-Sforza LL, Edwards AWF (1967). Phylogenetic analysis: models and estimation procedures. Am J Hum Genet 19: 233-257.

Chapuis MP, Estoup A (2007). Microsatellite null alleles and estimation of population differentiation. Mol Biol Evol 24: 621-631.

Charlesworth D, Willis JH (2009). The genetics of inbreeding depression. Nat Rev 10: 783-796.

Chybicki IJ, Burczyk J (2009). Simultaneous estimation of null alleles and inbreeding coefficients. J Hered 100: 106-113.

Chybicki IJ, Burczyk J (2010). nm + : software implementing parentage-based models for estimating gene dispersal and mating patterns in plants. Mol Ecol Resources 10 1071-1075.

Coates DJ, Sampson JF, Yates CJ (2007). Plant mating systems and assessing population persistence in fragmented landscapes. Aust J Bot 55: 239-249.
Duminil J, Hardy OJ, Petit RJ (2009). Plant traits correlated with generation time directly affect inbreeding depression and mating system and indirectly genetic structure. $B M C$ Evol Biol 9: 177-191.

Earl DA, von Holdt BM (2012). STRUCTURE HARVESTER: a website and program for visualizing STRUCTURE output and implementing the Evanno method. Conserv Genet Resour 4: 359-361.

Eckert CG, Kalisz S, Geber MA, Sargent R, Elle E, Cheptou P-O et al. (2010). Plant mating systems in a changing world. Trends Ecol Evol 25: 35-43.

Elliott CP, Byrne M (2005). Isolation and characterisation of microsatellites in the woody shrub, Calothmanus quadrifidus (Myrtaceae). Mol Ecol Notes 5: 757-759.

Excoffier L, Laval G, Schneider S (2005). Arlequin ver 3.0: an integrated software package for population genetic data analysis. Evol Bioinform Online 1: 47-50.

Felsenstein J (1989). phylip_Phylogeny Inference Package (Version 3.2). Cladistics 5: $164-166$.

Finger A, Kettle CJ, Kaiser-Bunbury CN, Valentin T, Doudee D, Matatiken D et al. (2011). Back from the brink: potential for genetic rescue in a critically endangered tree. $\mathrm{Mol}$ Ecol 20: 3773-3784.

Gibson N, Yates C, Byrne M, Langley M, Thavornkanlapachai R (2012). The importance of recruitment patterns versus reproductive output in the persistence of a short range endemic shrub in a highly fragmented landscape of south western Australia. Aust J Bot 60: 643-649.

Harrison HB, Saenz-Agudelo P, Planes S, Jones GP, Berumen ML (2013). Relative accuracy of three common methods of parentage analysis in natural populations. $\mathrm{Mol}$ Ecol 22: 1158-1170.

Hobbs RJ, Yates CJ (2003). Impacts of ecosystem fragmentation on plant populations: generalising the idiosyncratic. Aust J Bot 51: 471-488.

Honnay O, Jacquemyn $\mathrm{H}$ (2007). Susceptibility of common and rare plant species to the genetic consequences of habitat fragmentation. Conserv Biol 21: 823-831.

Hopper SD (2009). OCBIL theory: towards an integrated understanding of the evolution, ecology and conservation of biodiversity on old, climatically buffered, infertile landscapes. Plant Soil 322: 49-86.

Jakobsson M, Rosenberg NA (2007). CLUMPP: a cluster matching and permutation program for dealing with label switching and multimodality in analysis of population structure. Bioinformatics 23: 1801-1806.

Jones OR, Wang J (2010). COLONY: a program for parentage and sibship inference from multilocus genotype data. Mol Ecol Resources 10: 551-555.

lost L (2008). GST and its relatives do not measure differentiation. Mol Ecol 17: 4015-4026.

Kalinowski ST (2005). HP-Rare: a computer program for performing rarefaction on measures of allelic diversity. $\mathrm{Mol}$ Ecol Notes 5: 187-189.

Kingman JFC (1982). The coalescent. Stochastic Proc. App/ 13: 235-248.

Lander TA, Boshier DH, Harris SA (2010). Fragmented but not isolated: contribution of single trees, small patches and long-distance pollen flow to genetic connectivity for Gomortega keule, an endangered Chilean tree. Biol Conserv 143 2583-2590.

Liu K, Muse SV (2005). POWERMARKER: integrated analysis environment for genetic marker data. Bioinformatics 21: 2128-2129.

Llorens TM, Byrne M, Yates CJ, Nistelberger HM, Coates DJ (2012). Evaluating the influence of different aspects of habitat fragmentation on mating patterns and pollen dispersal in the bird-pollinated Banksia sphaerocarpa var. caesia. Mol Ecol 21: 314-328.

Muller F, Voccia M, Bâ A, Bouvet J-M (2009). Genetic diversity and gene flow in a Caribbean tree Pterocarpus officinalis Jacq.: a study based on chloroplast and nuclear microsatellites. Genetica 135: 185-198.

Nybom H (2004). Comparison of different nuclear DNA markers for estimation of intraspecific genetic diversity in plants. Mol Ecol 13: 1143-1155.

Oddou-Muratorio S, Klein E (2008). Comparing direct vs. indirect estimates of gene flow within a population of a scattered tree species. $\mathrm{Mol}$ Ecol 17 2743-2754

Peakall R, Smouse PE (2006). GENELEX 6: genetic analysis in Excel. Population genetic software for teaching and research. Mol Ecol Notes 6. 288-295.

Piry S, Alapetite A, Cornuet J-M, Paetkau D, Baudouin L, Estoup A (2004). GeneClass2: a software for genetic assignment and first generation migrants detection. $J$ Hered 95 536-539.

Piry S, Luikart G, Cornuet J-M (1999). bottleneck: a computer program for detecting recent reductions in effective population size from allele frequency data. $J$ Hered 90 : 502-503.

Pritchard JK, Stephens M, Donnelly P (2000). Inference of population structure from multilocus genotype data. Genetics 155: 945-959.

Ritland K (2002). Extensions of models for the estimation of mating systems using n independent loci. Heredity 88: 221-228.

Robledo-Arnuncio JJ, Gill L (2005). Patterns of pollen dispersal in a small population of Pinus sylvestris L. revealed by total-exclusion paternity analysis. Heredity 94 $13-22$

Robledo-Arnuncio JJ, Navascués M, González-Martínez SC, Gil L (2009). Estimating gametic introgression rates in a risk assessment context: a case study with Scots pine relicts. Heredity 103: 385-393.

Rousset F (2008). GENEPOP'007: a complete re-implementation of the genepop software for Windows and Linux. Mol Ecol Resources 8: 103-106.

Sebbenn AM, Carvalho ACM, Freitas MLM, Moraes SMB, Gaino APSC, da Silva JM et al. 2011). Low levels of realized seed and pollen gene flow and strong spatial genetic structure in a small, isolated and fragmented population of the tropical tree Copaifera langsdorffii Desf. Heredity 106: 134-145. 
Severns PM, Liston A, Wilson MV (2011). Habitat fragmentation, genetic diversity, and inbreeding depression in a threatened grassland legume: is genetic rescue necessary? Conserv Genet 12: 881-893.

Slavov GT, Leonardi S, Burczyk J, Adams WT, Strauss SH, DiFazio SP (2009). Extensive pollen flow in two ecologically contrasting populations of Populus trichocarpa. Mol Ecol 18: 357-373.

Wang J (2004). Application of one-migrant-per-generation rule to conservation and management. Conserv Biol 18: 332-343.

Wang J, Santure AW (2009). Parentage and sibship inference from multilocus genotype data under polygamy. Genetics 181: 1579-1594.
Wang R, Compton SG, Chen X (2011). Fragmentation can increase spatial genetic structure without decreasing pollen-mediated gene flow in a wind-pollinated tree. $\mathrm{Mol}$ Ecol 20: 4421-4432.

Wright S (1951). The genetical structure of populations. Ann Eugenics 15: 323-354.

Yates CJ, Elliott C, Byrne M, Coates DJ, Fairman R (2007). Seed production, germinability and seedling growth for a bird-pollinated shrub in fragments of kwongan in south-west Australia. Biol Conserv 136: 306-314.

Young AG, Boyle T, Brown T (1996). The population genetic consequences of habitat fragmentation in plants. Trends Ecol Evol 11: 413-418.

Supplementary Information accompanies this paper on Heredity website (http://www.nature.com/hdy) 